

\section{Diálogos narrativos: as linhas de aproximação entre o audiovisual e os video games}

\section{Narrative dialogues: parallels between the audiovisual and video games}

\section{Resumo}

Pretendemos analisar as zonas de intersecção entre a linguagem audiovisual, sobretudo a cinematográfica, e a dos video games. Para tanto, examinamos o percurso desse processo observando as relações dialógicas estabelecidas entre esses dois campos discursivos a partir das franquias, adaptações e influências mútuas registradas em suas narrativas. Utilizaremos estudos sobre o dialogismo bakhtiniano a partir de Robert Stam e do próprio Mikhail Bakhtin, além de pesquisas sobre teoria da adaptação propostas por Linda Hutcheon. Como objeto central e produto dessas trocas entre dispositivos estéticos, traremos uma análise mais detalhada do jogo Red Dead Redemption (2009, Rockstar games), assinalando questões relacionadas à mise-en-scène do video game, utilizando os preceitos teóricos de $\mathrm{Da}$ vid Bordwell e Kristin Thompson.

\section{Palavras-chave}

Cinema; video games; dialogismo; mise-en-scène; adaptação.

\section{Abstract}

We intend to analyze the parallels between the audiovisual language, specifically the film language, and the video games. To do so, we will discuss the dialogic relationships built among these two discursive fields, using as starting points the franchises, the adaptations and the mutual influences that can be perceived in these medias. As theoretical bases, we will use the dialogical principles of Mikhail Bakhtin, Robert Stam's studies about those principles, and Linda Hutcheon's researches on theories of adaptation. As a product of these esthetical exchanges, we will analyze the game Red Dead Redemption (2009, Rockstar Games), discussing about the use of mise-en-scene. In order to do so, we will apply David Bordwell and Kristin Thompson's theories about the subject.

\section{Keywords}

Film studies; video games; dialogism; mise-en-scène; adaptation. 


\section{"Êxodo na América" - Elementos} introdutórios ${ }^{3}$

Neste trabalho pretendemos analisar as zonas de intersecção entre a linguagem audiovisual, sobretudo a cinematográfica, e a dos video games. Para tanto, devemos examinar o percurso desse processo observando as relações dialógicas estabelecidas entre esses dois campos discursivos a partir adaptações e influências mútuas registradas em suas narrativas.

Nesse sentido, utilizaremos estudos sobre o dialogismo bakhtiniano a partir de Robert Stam, além de pesquisas sobre teoria da adaptação propostas por Linda Hutcheon. Como objeto central e produto dessas trocas entre dispositivos estéticos, traremos uma análise mais detalhada do jogo Red Dead Redemption (Rockstar games, 2009), assinalando questões relacionadas à mise-en-scène do video game. Para tal, utilizaremos os preceitos teóricos de David Bordwell e Kristin Thompson aplicados ao game.

O estudo se propõe a examinar a composição de cena a partir de diversos aspectos como cenários, figurino, iluminação, tempo e espaço. Essa escolha se deu pelo valor simbólico que a mise-en-scène adquire no andamento do game Red Dead Redemption, que, além de situar determinado momento histórico, pode ter influência na experiência de jogo.

Uma prerrogativa de difícil manejo quando discutimos essa temática é delimitar o objeto de estudo. Teremos o cuidado de não exceder o recorte aqui realizado, procurando fazer com que as informações se consubstanciem em conhecimento. Além disso, reconhecemos ainda a ampla extensão de propostas que, obviamente, não se esgotam naquilo que apontaremos nesse trabalho.

Nesta análise, partimos da noção do video game enquanto discurso específico, com características bastante sedimentadas e que, assim como o cinema, retrabalhou as inúmeras influências provenientes de campos artísticos, como quadrinhos e literatura, para fundar uma linguagem própria como meio de produção que também se relaciona estreitamente com a tecnologia. No caminho de volta, as influências também podem ser destacadas quando observamos como os video games realizam essa contrapartida em outras linguagens artísticas.

\section{Diálogos anteriores:}

\section{o cinema no video game}

Quando voltamos um pouco no tempo para examinarmos o desenvolvimento das adaptações de longas-metragens para os video games, é possível certamente assinalar aqui, dentre outras possibilidades, o jogo $\mathrm{Mi}$ chael Jackson's Moonwalker, de 1990, baseado no filme Moonwalker (Moonwalker, Jerry Kramer, Jim Blashfield, Colin Chilvers, 1988). Trata-se de um caso bastante comum até os dias de hoje, no qual o jogo reutiliza e, por vezes, ressignifica referências da história da produção cinematográfica, fazendo com que o jogador vivencie e interaja a partir de comandos de ação sobre a(s) personagem(s) protagonista(s) do filme.

É importante destacar que a relação estabelecida por parte daquele que tem contato com esses produtos, seja com o filme, seja com o jogo (ou mesmo com ambos), não respeita a sequência cronológica de lançamentos de cada produção. Em outras palavras, muitas vezes o jogador não experienciou a obra cinematográfica, assim como é bastante lógica a ideia de que muitos espectadores não tiveram contato com o game.

Por um lado, o caminho mais comum por parte do interlocutor é realizar o elo estabelecido entre ambas. Como sugere Hutcheon, o consumo de adaptações se estabelece a partir de uma demanda perene que atrai as pessoas por meio de um prazer que "advém simplesmente da repetição com variação, do conforto do ritual combinado à atração da surpresa. O reconhecimento e a lembrança são parte do prazer (e do risco) de experienciar uma adaptação" (Hutcheon, 2011, p. 25).

A influência do cinema atua de outras maneiras, contribuindo para a elaboração de jogos como Pink panther goes to Hollywood, de 1993. Baseado no desenho animado, o game tem sua narrativa desdobrada nos cenários de filmes de narrativa clássica norte-americana. $O$ jogo é subdividido em fases que tem como pano de fundo, entre outras ambiências, o faroeste, a casa mal assombrada, além do backstage de gravação, onde a pantera cor-de-rosa tem que se esquivar de holofotes e câmeras que tentam atacá-la.

$O$ registro desse jogo se deve à necessidade de observarmos como, aos poucos, numa trajetória inversa, o cinema e o audiovisual foram também incorporando os video games em suas narrativas. Por vezes, para enfatizar certa caracterização de personagens a partir de uma utilização bastante coadjuvante e, em outros momentos, na inserção de elementos característicos da linguagem dos games eletrônicos em suas narrativas, como veremos mais à frente.

\section{Diálogos contemporâneos:}

uma via de mão dupla

O trajeto das influências múltiplas foi aos poucos se aproximando de uma via de mão dupla, onde percebemos que as contribuições desses dois campos discursivos acabam, por vezes, relacionando-se simbioticamente. Se antes a contrapartida dos video games frente à forte presença do cinema e do audiovisual deixava um rastro quase indetectável, hoje podemos enumerar sem maiores dificuldades alterações nesse processo. 
É possível, dessa forma, rastrear elementos estéticos da linguagem dos games em produções para séries de TV, em vídeos para internet e filmes das mais variadas metragens. A contribuição não se aplica tão somente à materialização dos consoles na diégese desses veículos discursivos. Em outras palavras, a representação vai além da mera imagem de uma pessoa jogando video game. Ela se desdobra no uso de códigos bastante peculiares da linguagem desenvolvida nos consoles para gerar significados e efeitos de sentido nessas produções com características matizadas.

Para pensarmos a respeito desses imbricamentos, baseamo-nos em estudos do pesquisador Robert Stam, que pode ser visto como o elo entre o pensador russo Mikhail Bakhtin e o cinema. Os estudos do pensador norte-americano estabelecem essa ponte, através da qual são debatidos conceitos como o dialogismo, que "sugere que todo e qualquer texto constitui uma interseção de superfícies textuais" (Stam, 2003, p.225226). Desdobrando um pouco mais a análise do termo, é possível constatar que esse diálogo é estabelecido intertextualmente e se refere

às possibilidades infinitas e abertas produzidas pelo conjunto das práticas discursivas de uma cultura, a matriz inteira de enunciados comunicativos no interior da qual se localiza o texto artístico, e que alcançam o texto não apenas por meio de influências identificáveis, mas também por um sutil processo de disseminação (Stam, 2003, p.226).

Processos como esses também podem ser identificados na construção das narrativas dos games, nas referências implícitas e explícitas a obras provenientes de outros campos discursivos ou até mesmo na influência de jogos de outrora. Podem ser facilmente assinaladas nas propostas de adaptações declaradas, como o Michael Jackson's Moonwalker.

No entanto, os intertextos podem se revelar, sobretudo, nas sutilezas de certos encadeamentos estéticos e narrativos, a exemplo do jogo The last of us (2013), da produtora Naughty dog. O video game conta a história de pessoas que lutam para sobreviver a um apocalipse zumbi. O contexto dialógico contribui para que indivíduo que cria atue como "um agente que dinamicamente orquestra textos e discursos preexistentes. (...) A intertextualidade não se limita a um único meio; ela autoriza relações dialógicas com outros meios e artes" (Stam, 2003, p.227).

Justamente por isso, podemos elencar outras referências contemporâneas do gênero, a exemplo do filme Zumbilândia (Zombieland, Ruben Fleischer, 2009); e The walking dead, série americana adaptada de uma história em quadrinhos homônima, ambas ainda em produção. No primeiro caso, o longa ajuda a desconstruir a versão estritamente trágica da mortandade ao utilizar uma narrativa cômica para representar o entorno apocalíptico dos sobreviventes. A série também complexifica o universo zumbi, colocando em choque a alteridade dos indivíduos na agrura de se lidar com outros seres humanos, por vezes, mais perigosos que os próprios mortos-vivos.

Apesar de coabitar uma atmosfera de produções (narrativas lineares) mais voltadas para a violência explícita e até mesmo gratuita, o jogo emprega um viés de produção mais complexo. The last of us possui seus alívios cômicos e por vezes tonalidades de um colorido mais vibrante, com ares de esperança, aproximando-se de Zumbilândia, numa dinâmica que deixa espaço também às nuances acinzentadas de valoração pessimista utilizadas frequentemente em The walking dead. O game adere ainda a uma asserção que se dedica não somente ao ambiente de terror por conta da ameaça dos mortos-vivos, assim como a série. Por isso, acaba trazendo uma perspectiva mais profunda do ser humano em situações-limite, como as relações fraternas e amorosas dos sobreviventes num ambiente adverso, além, claro, da problemática matricial do indivíduo: a dificuldade de lidar com a morte.

O vínculo entre o audiovisual e os video games não se detêm tão somente às adaptações, mas também estão presentes num tipo de influência que contribuiu esteticamente e diegeticamente na arquitetura de algumas histórias contadas a partir dos games. Para ilustrar um caso em que a elaboração de um texto audiovisual foi arquitetado a partir de códigos provenientes da linguagem utilizada nos video games, podemos citar o episódio Digital Estate Planning, da série americana Community.

O programa de TV conta a história de Jeff Winger (Joel Mchale), um advogado que tem sua licença suspensa porque seu diploma é falso. Por conta disso, Jeff acaba se matriculando em uma universidade comunitária onde ele tem contato com alunos e professores bastante inusitados. Em Digital Estate Planning, Jeff e alguns colegas de turma tem que ajudar Pierce Hawthorne (Chevy Chase) a reivindicar a herança de seu pai, Cornelius Hawthorne. Para isso, eles têm que vencer num jogo de video game. No episódio, os personagens se transmutam em seus avatares de jogo, ganhando vida e voz na narrativa do video game.

Dentre os recursos que materializam essa particularização estética, podemos citar a trilha sonora, que, seja no tema de abertura da série ou no próprio de- 
senvolvimento do episódio, distancia-se da usada habitualmente no programa e passa a ser marcada pela performance de sintetizadores tipicamente utilizados em jogos da década de 1980. A computação gráfica empregada na composição dos cenários e dos personagens dentro do game também remete à mesma época, na qual ficaram bastante conhecidos os jogos da série Super Mario Bros, da Nintendo. A imagem pixelizada é outro elemento que dá ênfase à estética dos jogos de video game, além de dados narrativos bastante peculiares, como os fogos de artifício que caracterizam a vitória do(s) jogador(es) ao final do game.

Numa análise voltada para o estudo da Pós-modernidade presente no cinema, Renato Pucci assinala a recorrência da "impureza em relação a outras artes e mídias", o que faz com que o "hibridismo transtextual [transforme-se] em valor positivo" (Pucci, 2008, p.199). Fazemos aqui uma ponte com o audiovisual para compreendermos justamente que esses valores provenientes da intersecção e impregnação de outros campos discursivos acabam produzindo textos mais abertos a novas propostas narrativas gerando formas transversais de representação, como veremos na análise a seguir.

\section{A redenção pela morte}

rubra e a mise-en-scène

Red Dead Redemption conta a história de John Marston, um fora-da-lei que tentou abandonar a vida de crimes e viver com sua família, esposa e filho, em um rancho afastado dos olhos da polícia. No entanto, seus parentes foram sequestrados por agentes federais, e, para libertá-los, ele é coagido a perseguir seus antigos parceiros. $O$ jogo começa quando John Marston chega à cidade de Armadillo, onde um de seus comparsas estava atuando. Uma longa jornada tem início, levando a personagem a diversos lugares diferentes. Quando ele termina a tarefa, reúne-se de volta com sua família, até o dia em que os mesmos agentes que o abordaram no início do jogo retornam para matá-lo, pois, não poderiam deixar um criminoso solto após tantos prejuízos causados. Anos depois, seu filho Jack reaparece, agora crescido e mais velho, e toma vingança em cima do mesmo agente que assassinou seu pai.

Escolhemos a categoria da mise-en-scène pelo valor simbólico que a composição de cenas ganha na narrativa do game Red Dead Redemption, característica que aproxima o objeto em análise da linguagem cinematográfica. Os aspectos da mise-en-scène, conforme os dizeres de Bordwell e Thompson (1997), serão explicitados separadamente a seguir, e conforme avançamos na análise, paralelos com as mecânicas internas ao jogo serão estabelecidos. Esperamos, assim, que o leitor tenha um quadro amplo dos diálogos linguísticos entre o cinema e o video game.

Antes de nos deter na análise, porém, cabe-nos levantar um ponto de distinção importante entre as duas mídias aqui estudadas, no tocante à classificação de gênero. Nos filmes, essa distinção costuma se dar por convenções narrativas - filmes de terror, romance, comédia. Nos games, contudo, essa distinção se baseia não em convenções de narrativas - muitos jogos sequer trazem histórias a serem narradas - mas sim pelas experiências de interação do jogador com a mídia. Jogos de ação, por exemplo, têm em si mecânicas de gameplay comuns a outros de seu gênero, como combates.

No que diz respeito ao objeto em análise, Red Dead Redemption se trata de um jogo de ação-aventura com cenário aberto, trazendo embutidas mecânicas de combate, gerenciamento de recursos (munição, comida, dinheiro etc.), e um cenário com o qual o jogador interage diretamente, podendo escolher entre diversos cursos de ação, proporcionando, assim, a ilusão de escolha ao jogador - o final já está escrito independente de suas ações. Além disso, ele tem um fio narrativo que conduz o jogador por meio de investigações, e é permeado de pequenos outros jogos característicos do gênero de aventura.

Já que a presente pesquisa se propõe a apresentar os paralelos de semelhança entre duas diferentes mídias, tomaremos emprestado os conceitos acerca do termo mise-en-scène da teoria do cinema, ressaltando uma questão de terminologia em comum entre os dois campos aqui estudados: tanto na crítica fílmica quanto na de games, termos como cenário, fotografia e figurino são utilizados. Há, contudo, termos específicos à área dos video games, como cut-scene, para se referir às animações durante as quais o jogador não interage com a mídia; gameplay, para se referir à experiência de jogo; $\mathrm{e}$ episódio ou capítulo, para tratar de jogos que dividem suas narrativas em capítulos, como os de um romance.

De acordo com Bordwell e Thompson, o termo mise-en-scène é utilizado para se referir

ao controle do diretor sobre o que aparece no enquadramento do filme. Como seria de se esperar pelas origens teatrais do termo, inclui aqueles aspectos que se justapõem à arte do teatro: o cenário, a iluminação, o figurino e o comportamento dos personagens. Ao controlar a mise-en-scène, o diretor prepara a encenação para a câmera"4 (1997, p. 169).

Um ponto importante a ser considerado quando analisando a composição de cena de qualquer texto que faça uso da categoria não é seu suposto realismo, mas sim sua função narrativa, o papel que ela desempenha 
na construção de sentido. E, uma vez que este trabalho se propõe a analisar uma mídia baseada em computação gráfica - e, portanto, nem sempre com aspecto realista - teremos por norte esse princípio.

“Lugar esquisito prum sujeito decente visitar, se o senhor num se importar que eu fale" - Cenário

Na narrativa cinematográfica, o cenário pode ganhar grande importância dentro do desenvolver da narrativa. De acordo com Bordwell e Thompson, "ele não precisa ser apenas um contêiner para os eventos humanos, mas também entrar na ação narrativa dinamicamente $^{5 \prime \prime}(1997$, p. 172).

Em Red Dead Redemption, os cenários são bem desenvolvidos visualmente, tomando por referências cenários reais. Produzidos de maneira digital, eles remetem de maneira clara aos cenários dos filmes de western hollywoodianos, como podemos ver nas figuras 1, 2, 3 e 4 .

Apesar das possiblidades de variação oferecida pelo meio digital, a "montagem" do jogo se inspira na decupagem clássica. No campo visual, a ilusão dificilmente é quebrada, com exceção dos momentos em que o gameplay precisa se sobrepor ao ilusionismo: os locais de aquisição de itens sempre são convenientemente próximos uns dos outros; as ações de compra têm janelas próprias, embora elas tenham um visual inspirado pela temática do jogo. Diferente do efeito que a adoção de tal estética teria sobre uma mídia audiovisual - como o exemplo citado anteriormente da série de TV Community - nos games essa "quebra de ilusão"6 não é incomum. Habituado à interface e às necessidades individuais dos jogos eletrônicos, o jogador geralmente não vê problemas em passear entre diferentes formas de interação com a mídia.

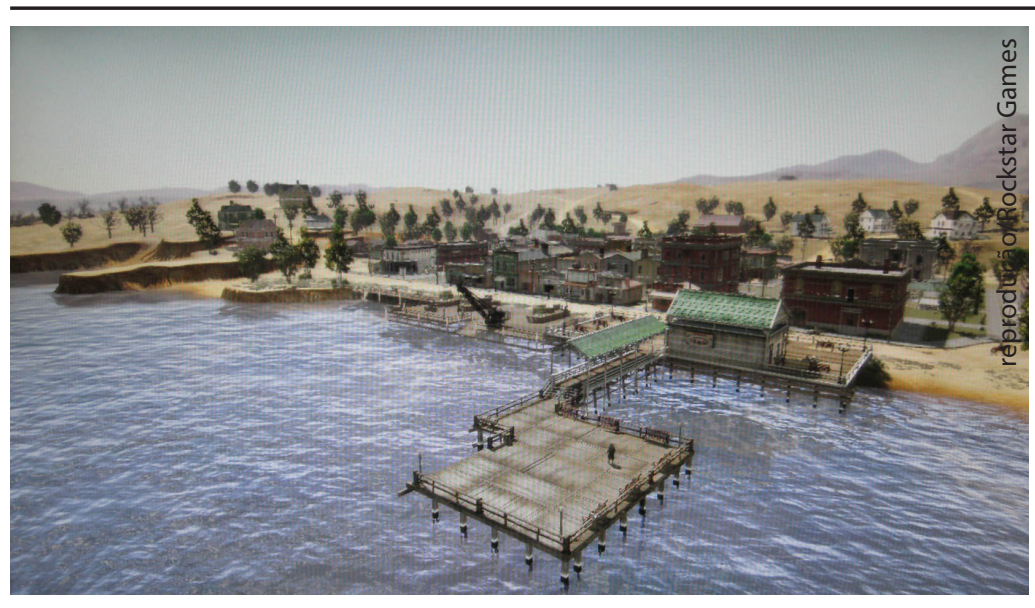

Figura 1: Cenário de Red Dead Redemption

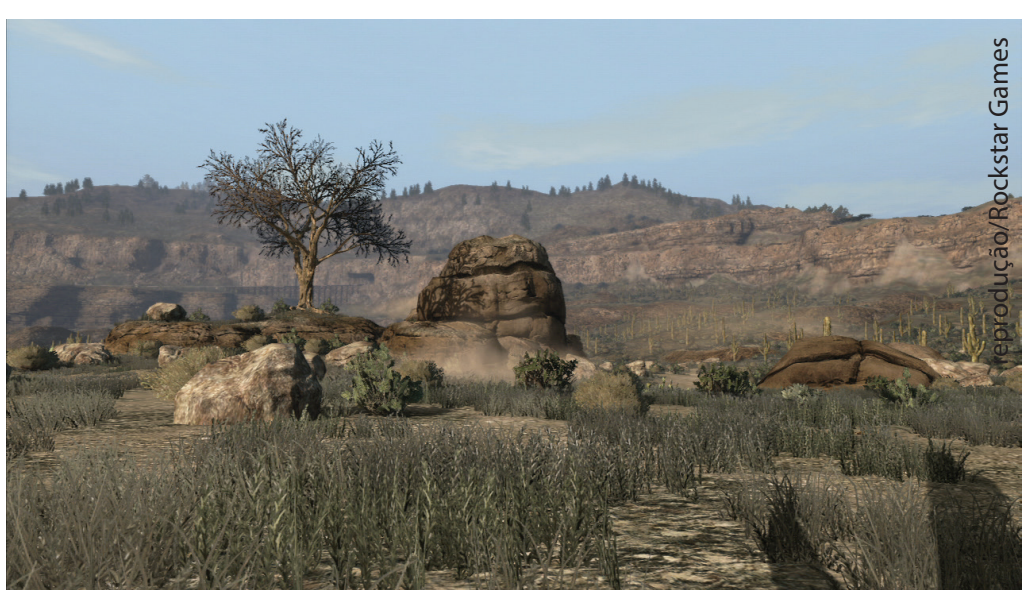

Figura 3: Cenário de Red Dead Redemption

Um outro diálogo interessante entre o gênero western e o jogo em estudo está nos momentos de duelos. Não é incomum que, durante o jogo, um desconhecido aleatório solte provocações, incitando o jogador a duelar. Se o jogador escolher seguir por esse curso, o ângulo de visão muda, bem como a jogabilidade e o andamento narrativo: adota-se uma câmera lenta enquanto os dois lados se armam, até que um dos lados dê seus tiros e atinja o alvo (figuras 5 e 6).

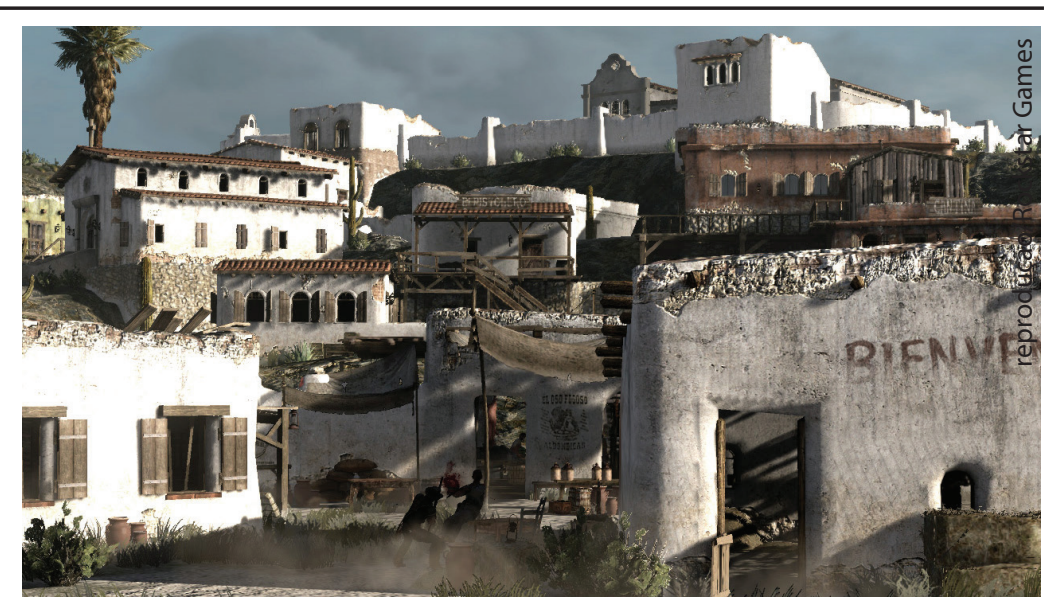

Figura 2: Cenário de Red Dead Redemption

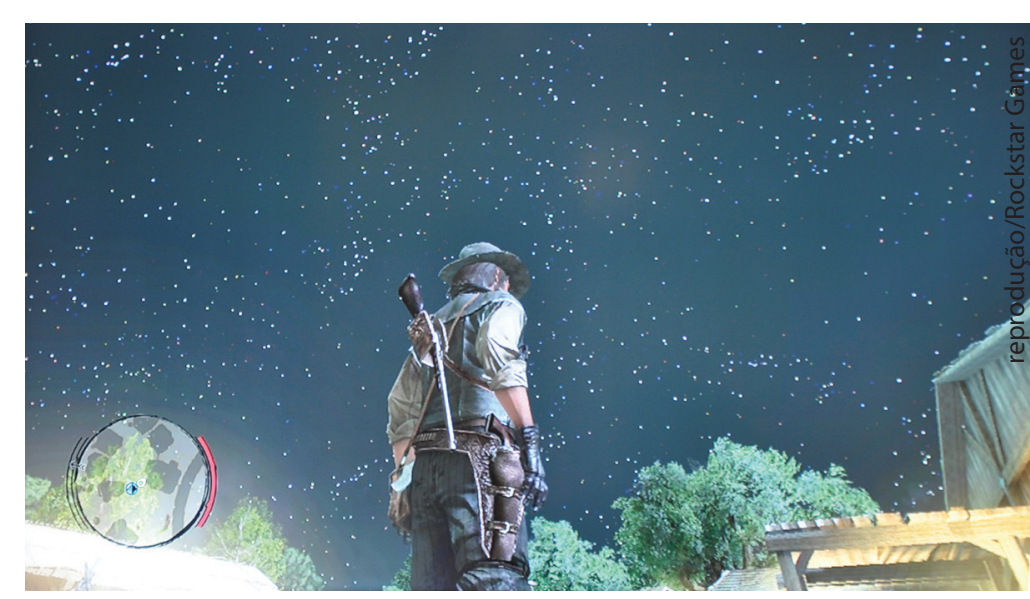

Figura 4: Cenário de Red Dead Redemption

A vastidão das paisagens, as cidades decadentes em uma terra onde as leis são aplicáveis com tons duvidosos de moralidade, remetem à narrativa do protagonista John Marston: sua jornada em busca da redenção por erros do passado é longa e solitária. Na maior parte do jogo, porém, os cenários não ganham aspecto de representação psicológica ou semelhante, limitando-se a um efeito simulacionista de conter a ação narrativa no ambiente retratado do interior dos Estados Unidos em

65 PORTO ALEGRE | v. 19 | n. 32 | 2014 | pp. $61-69$ Sessões do Imaginário 


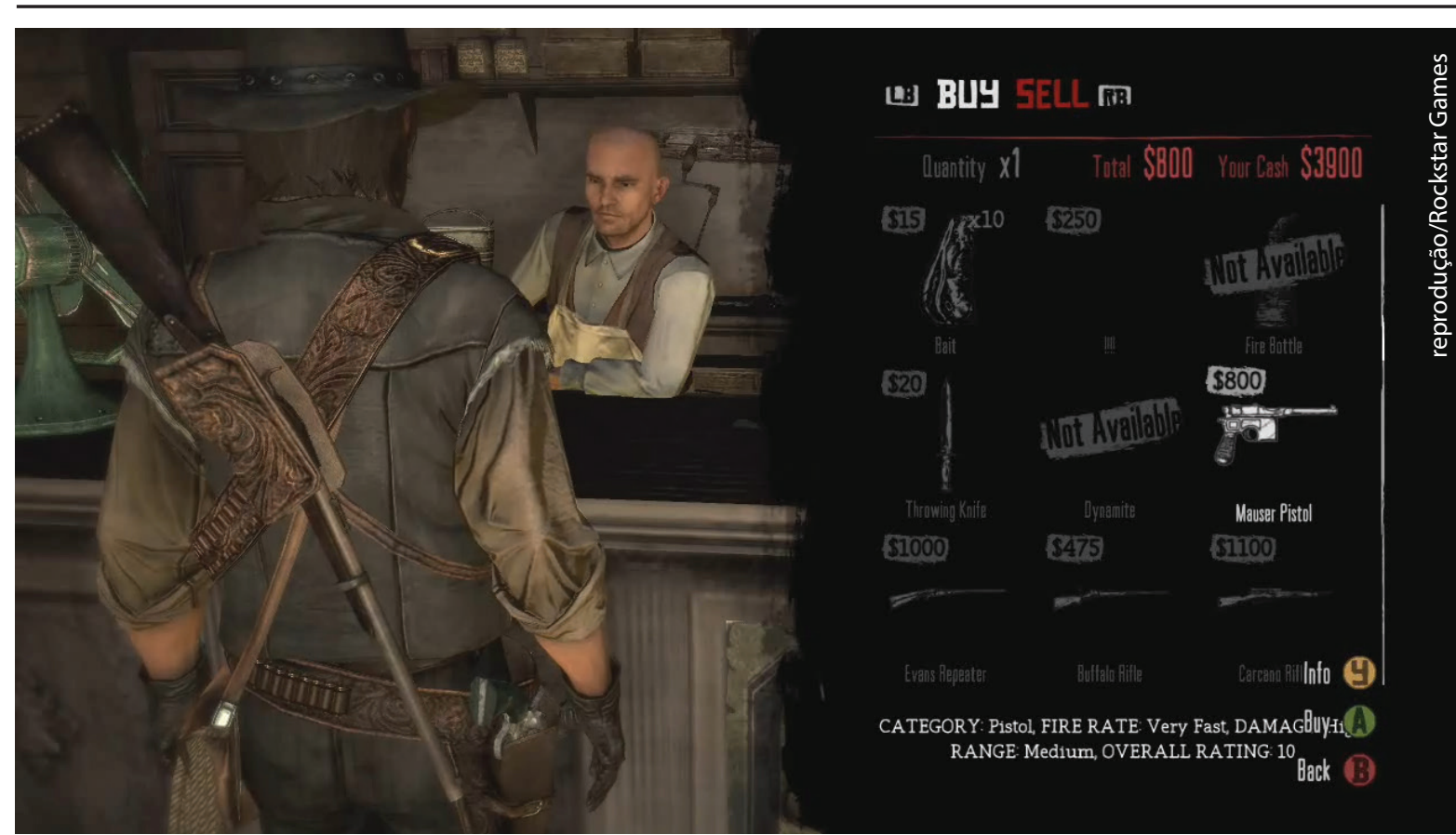

Figura 5: Imagem de Red Dead Redemption

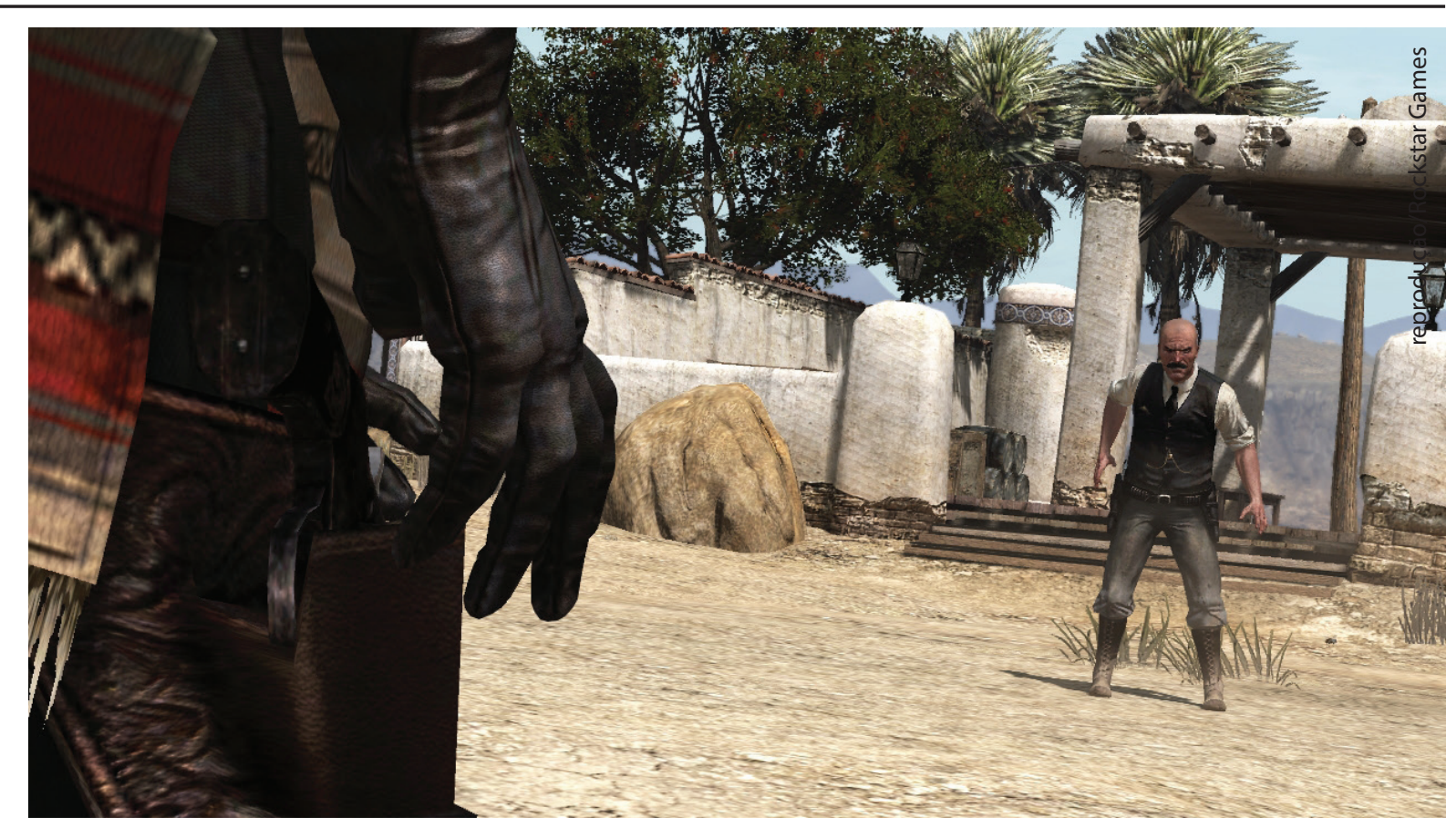

Figura 6: Cenário de Red Dead Redemption tempos de tentativas de expansão para o Oeste. Não há algum uso, por exemplo, de representação do cenário ou espaço como reflexo psicológico das emoções das personagens, o que seria um uso possível dentro das possibilidades da manipulação digital.

\section{"Nunca confiei em um homem}

de gravata" - Figurino

De acordo com Bordwell e Thompson, assim como o cenário, "o figurino pode ter funções específicas no todo do filme, e o alcance de possibilidades é amplo" $\left(1997\right.$, p. 176) ${ }^{7}$. As vestimentas e a maquiagem de determinada personagem podem carregar grande valor simbólico, falando de maneira não verbal sobre diversos aspectos das personagens, desde sociais, como a posição que ocupam, indicações de profissão, ou aspectos psicológicos (em momentos sombrios, uma personagem aparecer vestindo roupas escuras, por exemplo).

Em Red Dead Redemption, o trabalho de figurino tem como objetivo principal caracterizar o ambiente, de maneira análoga à do cenário. Uma mecânica de jogo que chama a atenção, porém, são as várias possibilidades de roupas que a personagem pode vestir no decorrer da história, e os efeitos que isso pode acarretar dentro da experiência de jogo. Ao usar o "figurino de cavalheiro" (gentleman's outfit, no original), é permitido trapacear em jogos de cartas, como pôquer. Ao vestir as roupas características das gangues de foras-da-lei encontradas no cenário, o jogo se modifica; eles não são impelidos a ver John Marston como um estranho no primeiro contato, o que pode dar alguma vantagem estratégica ao gameplay, mas, quando lidando com ho- mens da lei, eles serão mais hostis, podendo atacar a personagem sem aviso prévio.

Um outro uso do figurino é o de demonstrar as funções narrativas de algumas personagens. Os agentes federais encontrados por Marston no início e nos momentos finais do jogo estão sempre vestidos de terno e gravata, indicando sua posição social e também construindo os antagonistas em relação à personagem. Há também o Marshal Johnson, o agente da lei da pequena cidade de Armadillo: seu figurino no geral é simples e prático, com exceção da estrela prateada que exibe no peito, indicando sua função. Isso serve não apenas para o jogador, que é capaz de fazer a conexão com diversos outros filmes do gênero western, mas também para sua construção dentro da narrativa, como podemos atestar nas figuras 7 e 8 .

66 PORTO ALEGRE | v. 19 | n. 32 | 2014 | pp. 61-69 Sessões do Imaginário 


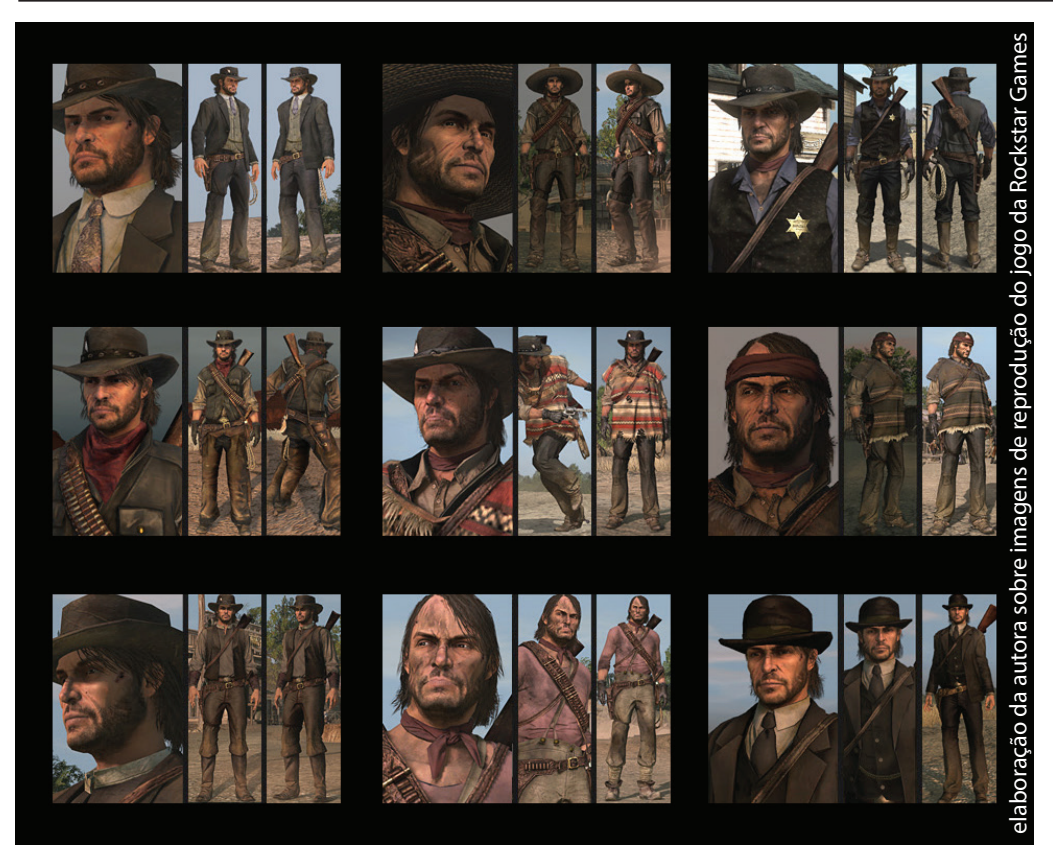

Figura 7: Personagens de Red Dead Redemption

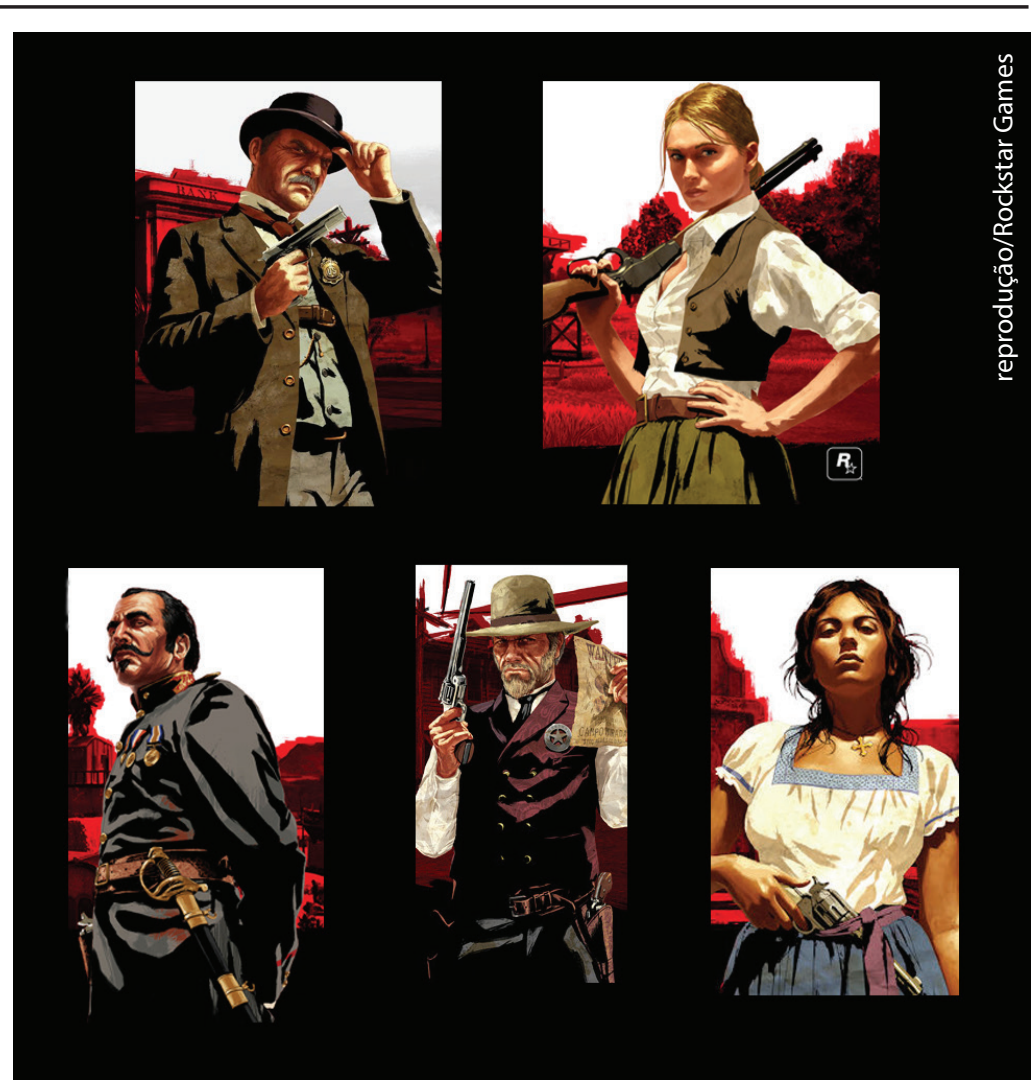

Figura 8: Personagens de Red Dead Redemption

mas permite aos cineastas criar composições claras para cada tomada" (1997, p. 181).

Um ponto importante a destacar aqui é que, durante o jogo, há variações na maneira de distribuir a luz a depender do momento. Durante as cut-scenes, a iluminação adotada não chega a ser realista (como é possível verificar nas cenas realizadas à noite, que são bem mais claras e visíveis do que uma demanda realista exigiria, o que apenas fortalece o propósito narrativo da iluminação, e não sua submissão a um suposto conceito de realismo), mas é verossímil. Vê-se a chama de uma vela tremulando sobre o rosto de alguma personagem em um ambiente escuro, por exemplo, assim como algum uso dramático da iluminação, quando ela chama a atenção para algum objeto ou ponto no espaço.

Em momentos de jogo, porém, a iluminação adota um caráter mais prático, facilitando a jogabilidade. Independentemente de ser dia ou noite, por exemplo, o gameplay não se modifica - os encontros aleatórios são os mesmos, e a iluminação não afeta o campo de visão do jogador, que pode enxergar os inimigos à mesma distância (vide figura 4). Tal uso não é uma regra dentro da mídia dos video games, porém há aqueles em que a iluminação - e a falta dela - influi diretamente na experiência de jogo, acrescentando mais dificuldades, ou impossibilitando a visão clara de algumas áreas.

"Você realmente é uma personagem, senhor Marston" - Expressões e atuação

De maneira semelhante a uma animação, a atuação em jogos de video games depende do trabalho em conjunto entre o aspecto visual e o sonoro: as personagens são dubladas, seus gestos e expressões são deliberadamente construídos e escolhidos pela equipe de produção. $\mathrm{E}$, assim como os outros aspectos da mise-en-scène, a atuação não deverá ser avaliada em níveis de realismo, mas sim dos propósitos narrativos que segue. Afinal, como medir o realismo do comportamento de uma personagem sobrenatural, por exemplo?

David Bordwell e Kristin Thompson dirão que

de maneira mais ou menos típica, a performance pode também ser situada em um contínuo de estilização. Uma longa tradição de atuação fílmica deseja alcançar a semelhança do que se toma por um comportamento realista. Esse senso de realismo pode ser criado ao dar aos atores pequenos traços de performance para que eles façam enquanto dizem suas falas $\left(1997\right.$, p. 137) ${ }^{8}$.

67 PORTO ALEGRE | v. 19 | n. 32 | 2014 | pp. 61-69 Sessões do Imaginário 
Os padrões de atuação em Red Dead Redemption são naturalistas, mantendo-se no limiar da decupagem clássica. As personagens estrangeiras são construídas geralmente seguindo estereótipos, mais especificamente um chinês, que figura em uma pequena narrativa sobre o vício em ópio, e um irlandês conhecido apenas por Irish, um fora-da-lei bêbado e de moralidade duvidosa.

Parte do jogo se passa em território mexicano, o que conduz Red Dead Redemption a uma variação espacial, e também de personagens apresentadas. Não raramente os mexicanos falam entre si em espanhol - idioma que o protagonista não conhece, mas os dizeres são traduzidos em legendas em inglês - e quando o fazem em inglês, trazem um sotaque típico encontrado em filmes hollywoodianos.

A construção dos tipos também variam conforme o local onde eles se apresentam. Ambientes campestres trazem personagens com um sotaque informal, cheio de contrações e gírias; enquanto nos cenários urbanizados temos personagens que falam de maneira mais clara, e cujos gestos e figurinos se adaptam ao ambiente.

\section{"Ninguém esquece nada. Ninguém} perdoa nada" - Sangue e redenção

Um aspecto importante na composição de cena no jogo Red Dead Redemption é a presença constante da cor vermelha, remetendo ao sangue e ao propósito da personagem em sua jornada: chegar aos lugares onde a lei não alcança e pôr um fim às atividades criminosas dos seus antigos parceiros de crime. John Marston é um criminoso que busca redenção, mas que, para isso, terá que usar as mesmas armas das quais tentou se afastar quando abandonou sua vida de crimes.

O sangue e a morte estão presentes desde a aliteração no título do jogo, e são constantes na jornada de Marston. Em um ambiente de tons pastéis e crus - o amarelo do deserto, o marrom do couro curtido, o negro da noite - o vermelho se destaca, ganhando tons saturados e aparecendo como um filtro que toma toda a tela. A estética que permeia o jogo também aparece na própria imagem de capa, que traz, numa tipografia estilizada e adequada ao tema western, quando John Marston encara o jogador em um leve contra-plongée, sua arma em primeiríssimo plano, desafiador.

As telas de pause, os menus do jogo, bem como as aberturas de capítulos seguem padrões semelhantes: baseando-se no forte contraste entre preto e esse vermelho saturado, as imagens apresentam-se ao jogador antecipando o final de John Marston, que não poderia ser diferente pela vida que levou. Seus atos não poderiam passar impunes, e em uma terra onde mesmo os agentes da lei não têm escrúpulos, não é possível enxergar uma redenção diferente de uma que não seja pelo sangue. Sabendo ser o verdadeiro alvo de seus algozes, Marston se sacrifica para salvar sua família, redimindo-se (confira as figuras 9 e 10).

Sua morte, porém, não traz o final do jogo. Jack Marston, seu filho, agora adulto, busca informações sobre o oficial Edgar, agora aposentado, o responsável pelo sequestro da sua família e pela morte do seu pai. O jovem segue os rastros do sujeito e o desafia para um último duelo, matando-o. Então, também em sangue, termina a narrativa de Jack, deixando seu final completamente em aberto. Não sabemos sobre seu destino, ou sobre suas possíveis intenções após ser realizada a vingança.

\section{"O último inimigo que deve ser destruído" - Conclusões}

A discussão acerca da idiossincrasia do discurso produzido nos video games nos mostra que o processo comunicativo e artístico está em constante movimento. Em

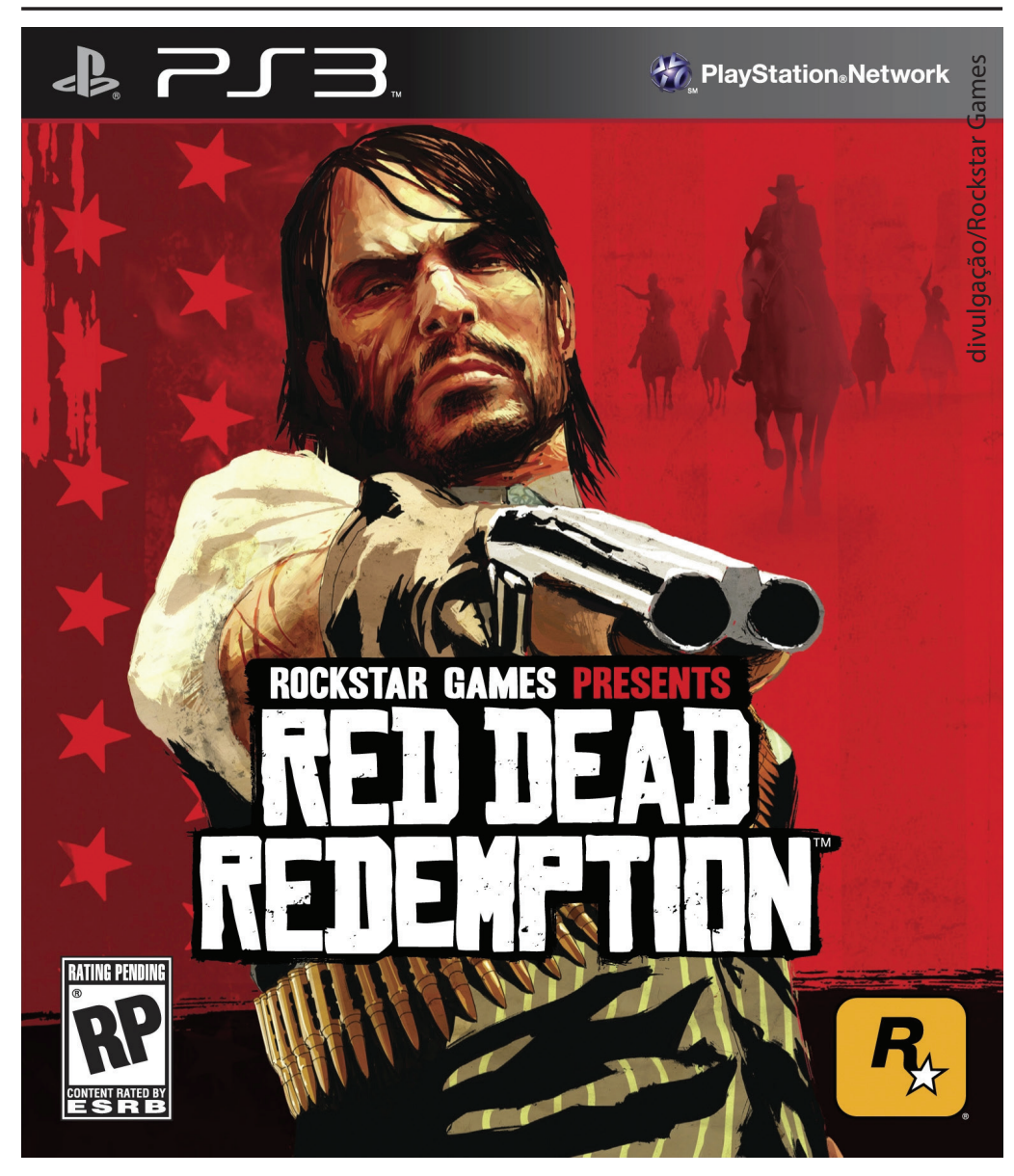

Figura 9: Tela inicial de Red Dead Redemption

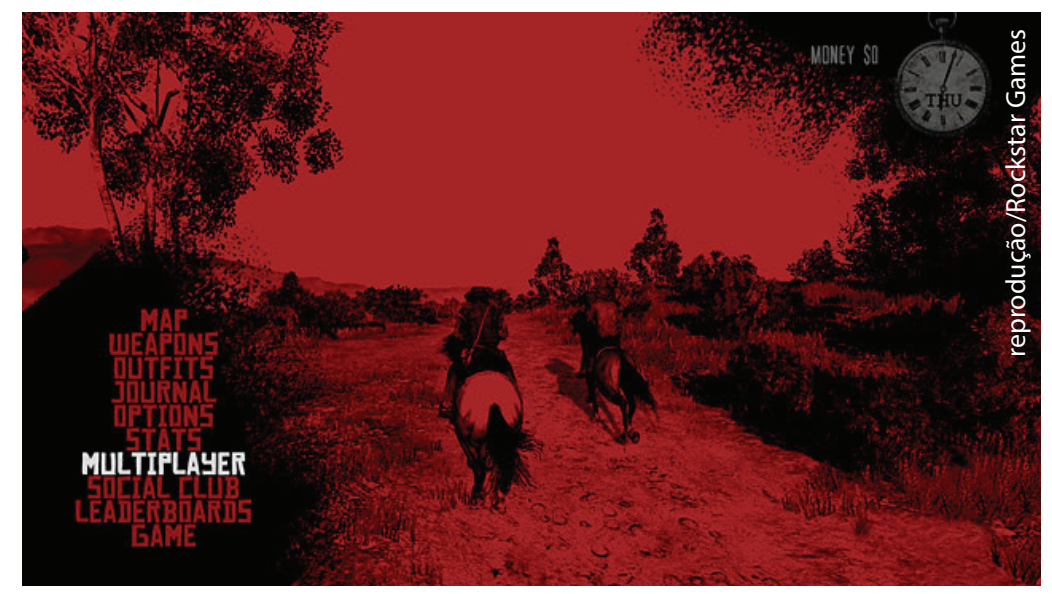

Figura 10: Imagem de Red Dead Redemption

68 PORTO ALEGRE | v. 19 | n. 32 | 2014 | pp. $61-69$ Sessões do Imaginário 
tempos de leituras de romances e quadrinhos a partir de tablets e smartphones, a tecnologia contribuiu também para o imbricamento das gramáticas específicas de cada meio. As influências passaram a atuar de maneira plural, onde diferentes dispositivos discursivos ressignificam códigos provenientes de meios difusores distintos.

Sobretudo por esses fatores, consideramos importante a análise dessa zona de fronteira, no âmbito da intersecção entre o audiovisual e os games. Trata-se de um campo de estudo que nos permite investigar, dentre outras coisas, formas diversas de construção identitária, a exemplo do modo como os gêneros são retratados nos jogos. Por isso, o horizonte que se descortina, nos faz observar com atenção a maneira como são construídos estereótipos e rompimentos, as representações que eles geram e os efeitos de sentido que produzem.

\section{Referências}

BORDWELL, David; THOMPSON, Kristin. Film Art: an introduction. New York: Mc-Graw Hill, 1997, $8^{\text {th }}$ edition.

HUTCHEON, Linda. Uma teoria da adaptação. Tradução André Cechinel. Florianópolis: Ed. da UFSC, 2011.

PUCCl, Renato. Cinema brasileiro pós-moderno: 0 Neon-realismo. Porto Alegre (RS): Editora Sulina, 2008.

STAM, Robert. Introdução à teoria do cinema. Campinas: Papirus, 2003.

- Teoria e prática da adaptação: da fidelidade à intertextualidade. In: CORSEUIL, A. R. (ed.). Ilha do desterro: Film Beyond Boundaries. Florianópolis, UFSC, $n^{\circ}$ 51, Jul/Dez 2006.
XAVIER, Ismail. 0 discurso cinematográfico: a opacidade e a transparência. São Paulo: Paz e Terra, 2008.

\section{Referências audiovisuais}

DARABONT, Frank. The walking dead. [Filme-vídeo]. Criação de Frank Darabont, produção de David Alpert, Gale Anne Hurd, Denise M. Huth, Robert Kirkman, Tom Luse e Greg Nicotero. EUA, 2010. color. son.

FLEISCHER, Ruben. Zumbilândia. [Filme-vídeo]. Produção de Gavin Polone. Estados Unidos, 2009. 88 min. color. son.

HARMON, Dan. Community. [Filme-vídeo]. Criação De Dan Harmon, produção de Jake Aust e Dan Harmon. EUA, 2009. color. son.

RAMER, Jerry; BLASHFIELD, Jim; CHILVERS, Colin. Moonwalker. [Filme-vídeo]. Produção de Paul Diener, Dennis E. Jones, Jerry Kramer e direção de Jerry Kramer. EUA, 1988. 93 min. color. son.

Red Dead Redemption. Playstation 3. Rockstar Games, 2009.01 disco blu-ray.

Notas

1 Doutorando em Letras pela Universidade Federal da Paraíba. Bolsista da Coordenação de Aperfeiçoamento de Pessoal de Nível Superior (Capes). (UFPB - Campus I, Conjunto Humanístico Bloco IV, Cidade Universitária, CEP: 58059-900, João Pessoa/PB, Brasil). E-mail: afonso780@yahoo.com.br.

2 Doutoranda em Literaturae Cultura pela Universidade Federal da Paraíba (UFPB - Campus I, Conjunto
Humanístico - Bloco IV, Cidade Universitária, CEP: 58059-900, João Pessoa/PB, Brasil). E-mail: allana. dilene@gmail.com.

3 Alguns intertítulos deste artigo foram nomeados com base em falas ou títulos de capítulos do game analisado.

4 "to signify the director's control over what appears in the film frame. As you would expect from the term's theatrical origins, mise-en-scéne includes those aspects of film that overlap with the art of theater: setting, lighting, costume, and the behavior of the figures. In controlling the mise-en-scéne, the director stages the event for the camera".

5 "it need not be only a container for human events but can dynamically enter the narrative action".

6 Utilizamos o termo "quebra de ilusão" neste trabalho no sentido de se referir a uma suposta falta de verossimilhança. No exemplo citado, normalmente em conglomerados urbanos as distâncias são maiores, e as localizações comerciais não ficam tão próximas entre si. O game prefere encurtar essas distâncias, para conveniência do jogador.

7 "Like setting, costume can have specific functions in the total film, and the range of possibilities is huge".

8 "Whether more or less typed, the performance can also be located on a continuum of stylization. A long tradition of film acting strives for a resemblance to what is thought of as realistic behavior. This sense of realism may be created by giving the actors small bits of business to perform while they speak their lines". 